\title{
Multiscale Characterization of Nanoengineered Fiber-Reinforced Composites: Effect of Carbon Nanotubes on the Out-of-Plane Mechanical Behavior
}

\author{
Carlos Medina, ${ }^{1}$ Eduardo Fernandez, ${ }^{1}$ Alexis Salas, ${ }^{1}$ Fernando Naya, ${ }^{2}$ \\ Jon Molina-Aldereguía, ${ }^{2}$ Manuel F. Melendrez, ${ }^{3}$ and Paulo Flores ${ }^{1,3}$ \\ ${ }^{1}$ Department of Mechanical Engineering (DIM), Faculty of Engineering (FI), University of Concepción, Concepcion, Chile \\ ${ }^{2}$ IMDEA Materials Institute, Getafe, Madrid, Spain \\ ${ }^{3}$ Advanced Nanocomposites Research Group (GINA), Department of Materials Engineering (DIMAT), \\ Faculty of Engineering (FI), University of Concepción, Concepcion, Chile
}

Correspondence should be addressed to Paulo Flores; pfloresv.udec@gmail.com

Received 18 January 2017; Revised 17 March 2017; Accepted 26 March 2017; Published 30 April 2017

Academic Editor: Zafar Iqbal

Copyright (C) 2017 Carlos Medina et al. This is an open access article distributed under the Creative Commons Attribution License, which permits unrestricted use, distribution, and reproduction in any medium, provided the original work is properly cited.

The mechanical properties of the matrix and the fiber/matrix interface have a relevant influence over the mechanical properties of a composite. In this work, a glass fiber-reinforced composite is manufactured using a carbon nanotubes (CNTs) doped epoxy matrix. The influence of the CNTs on the material mechanical behavior is evaluated on the resin, on the fiber/matrix interface, and on the composite. On resin, the incorporation of CNTs increased the hardness by $6 \%$ and decreased the fracture toughness by $17 \%$. On the fiber/matrix interface, the interfacial shear strength (IFSS) increased by $22 \%$ for the nanoengineered composite (nFRC). The influence of the CNTs on the composite behavior was evaluated by through-thickness compression, short beam flexural, and intraply fracture tests. The compressive strength increased by $6 \%$ for the $\mathrm{nFRC}$, attributed to the rise of the matrix hardness and the fiber/matrix IFSS. In contrast, the interlaminar shear strength (ILSS) obtained from the short beam tests was reduced by $8 \%$ for the nFRC; this is attributed to the detriment of the matrix fracture toughness. The intraply fracture test showed no significant influence of the CNTs on the fracture energy; however, the failure mode changed from brittle to ductile in the presence of the CNTs.

\section{Introduction}

The off-axis mechanical behavior of polymer matrix composites reinforced with long fibers depends on fibers and strongly on the matrix properties and the fiber-matrix interface. Micromechanical studies, both numerical and experimental, have shown that the material mechanical properties are sensitive to the matrix and fiber-matrix interface changes. For example, González and LLorca in [1] showed that the increment of the interface strength positively influences the transversal compressive strength. Totry et al. [2] studied the relevance of including the interface properties on the prediction of the mechanical behavior of a composite under a combined transversal stress state. Alternatively, Vaughan and McCarthy $[3,4]$ showed the effect of the matrix residual stresses due to curing cycles on the composite damage initiation. In addition, Lane et al. [5] found that matrix plasticity is a key factor on the reduction of the stress concentrators at the interface zone.

The inclusion of carbon nanotubes (CNTs) can improve the matrix and the fiber/matrix interface mechanical behavior, as shown in several studies [6-11]. However, $\mathrm{Ci}$ and Bai in [6] showed that the improvement of the matrix mechanical tensile properties is related to the polymer stiffness; that is, at lower stiffness, greater improvements can be obtained.

Godara et al. [12] evaluated two techniques for including CNTs on a fiber-reinforced composite (an epoxy glass fiberreinforced composite). One technique was fiber sizing and the other technique was mixing the CNTs on the resin, where an increase of $92 \%$ and $48 \%$ of matrix/fiber interface property 
(IFSS) was reported for the first and the second method, respectively. The same tendency, using different constitutive materials, mixing techniques, and measurement tests, can be found in other reports; for example, Chandrasekaran et al. [7] reported an increase of $36 \%$ on the IFSS, Godara et al. of $36 \%$ [12], Sager et al. of 71\% [13], Lv et al. of 175\% [14], Yang et al. of $190 \%$ [15], Li et al. of 40\% [16], and Wang et al. of 71\% [17]. Romanov et al. [18-20] used modeling to explain the effect of CNTs in the fiber/matrix interface, showing that the CNTs suppress the stress concentrations on the microlevel of the composite and therefore the IFSS improvement; nevertheless, experimental evidence is not easy to obtain. The overall increase should surely depend on the CNTs concentration, as shown numerically by Yang et al. [15]; however, for nanoengineered reinforced composites obtained by mixing and liquid transfer molding techniques, the CNTs concentration does not generally go beyond $0.5 \mathrm{wt} . \%$ due to the filtering effect; see, for example, the work of Gojny et al. [8] and JiménezSuárez et al. [21]. These studies show an improvement in the mechanical properties with a concentration of $0.5 \%$ by weight of CNTs; increasing these values no improvements are observed and even some properties decrease. For the reason described above, in this investigation the results will be reported only for a concentration of $0.5 \% \mathrm{wt}$. of CNTs in contrast to a concentration of $0 \%$ wt. CNTs.

This work presents a thorough experimental study focused on quantifying the influence of the CNT incorporation on the properties of the polymer matrix and the fiber-matrix interface and their contribution to the macroscopic mechanical behavior of the nanoengineered fiberreinforced composite (nFRC). To achieve this, an epoxy resin was doped with $\mathrm{CNTs}$ to manufacture a glass fiberreinforced composite. At the microscale, the effect of the CNTs on the mechanical properties of the pure resin was quantified by nanoindentation, fracture toughness, tensile, and compression tests. The influence of the CNTs on the fiber-matrix interface strength was assessed through pushout tests. Finally, the influence of the CNTs on the mechanical behavior of the nFRC was determined by intraply fracture and through-thickness compression tests, with the objective of determining the correlation between the effect of the CNTs on the micromechanical properties of the composite and its macroscopic mechanical behavior.

\section{Experimental}

2.1. Materials. The composite material consists on an epoxy matrix reinforced with glass fibers weave. The epoxy resin system is the L20 with the EPH 161 hardener from Momentive (distributed by R\&G composite, Germany). The reinforcement was a woven unidirectional glass fiber from PDInterglas, Germany (Interglas style 92145, currently named as UD220 g/m $\mathrm{m}^{2}$ ), with $207 \mathrm{~g} / \mathrm{m}^{2}$ in the warp direction and $13 \mathrm{~g} / \mathrm{m}^{2}$ in the fill direction. According to the data sheet the average glass fiber diameter was $9 \mu \mathrm{m}$ and the elastic modulus was $75 \mathrm{GPa}$. A masterbatch of nonfunctionalized multiwall CNTs was used as nanoreinforcement for the composite (Epocyl XC 128-06 CNTs masterbatch from Nanocyl, Belgium). The nanoreinforcement via masterbatch is chosen
TABLE 1: Fabricated materials.

\begin{tabular}{lc}
\hline Material & Constituents \\
E1 & Neat epoxy \\
E2 & Epoxy $+0.5 \%$ wt. CNTs \\
EG1 & Epoxy + glass fiber \\
EG2 & Epoxy + glass fiber $+0.5 \%$ wt. CNTs \\
\hline
\end{tabular}

to avoid CNTs suspension and to facilitate the dispersion process [10].

2.2. Material Fabrication. To obtain the nanoreinforced composite, the CNTs masterbatch was diluted in L20 epoxy resin by factor of 10 . The mixture was homogenized by mechanical stirring for 10 minutes at $1000 \mathrm{rpm}$. Subsequently, the resin was mixed with a hardener at a $4: 1$ ratio to obtain concentrations of CNTs in the composite of $0.5 \mathrm{wt} . \%$. Next, the mixture was degassed in an ultrasound bath for 15 minutes. The composites were manufactured by RTM; each mixture was introduced into a closed waxed mold of $100 \times 100$ $\times 4.3 \mathrm{~mm}^{3}$. The mold contained 25 plies of glass fiber oriented at $0^{\circ}$ to obtain a ca. $50 \%$ fiber volume fraction, according to the ASTM D 3171 standard. The procedure is similar for the fiber-reinforced composite, and the pure resin samples were manufactured by manual pouring into the same mold. Curing and postcuring occurred at room temperature for 24 hours and at $100^{\circ} \mathrm{C}$ for 15 hours in an oven, respectively. Table 1 describes the materials used in this study.

\subsection{Epoxy/CNTs Nanocomposite Mechanical Characteriza-} tion. Nanoindentation tests were performed using a Hysitron TI 950 Triboindenter instrument equipped with a Berkovich tip (10 specimens per material and at least 30 nanoindentations per specimen). The tests were carried out at a constant displacement rate of $25 \mathrm{~nm} / \mathrm{s}$ to a maximum load of $12 \mathrm{mN}$. The surfaces for nanoindentation were polished with a sequence of silicon carbide papers of 1000, 2000, and 4000 and then finished with diamond polishing pastes of $0.3 \mu \mathrm{m}$ and $0.1 \mu \mathrm{m}$. The elastic modulus and hardness parameters were computed from the load/displacement curves, following the Oliver and Pharr method [22].

An Instron 8801 universal testing machine was used to perform the tensile tests according to ASTM D638, the shear test according to ASTM D732 and the compression test according to ASTM D695 standards (10 tests per material for each case). A type IV sample was selected for the tensile test, at a cross-head speed of $5 \mathrm{~mm} / \mathrm{min}$, where an optical system based on digital image correlation (Aramis from $\mathrm{GOM}, \mathrm{GmbH}$ ) was used for the strain measurement. For the shear test, $50 \times 50 \mathrm{~mm}^{2}$ samples with $3 \mathrm{~mm}$ thicknesses were used, and the punch tool speed was $1.3 \mathrm{~mm} / \mathrm{min}$ to apply the load and compute the shear strength. For the compression tests, $10 \times 10 \mathrm{~mm}^{2}$ samples with $20 \mathrm{~mm}$ thicknesses were used, the speed was $3 \mathrm{~mm} / \mathrm{min}$, and, as before, an optical system was used for the strain measurement.

The fracture behavior was evaluated by means of a test according to the ASTM D 5045 standard using single-edge notched bending (SENB) specimens (5 tests per material for 
TABle 2: Properties of the epoxy/CNTs nanocomposite.

\begin{tabular}{lccccccc}
\hline Material & $\begin{array}{c}\text { Reduced } \\
\text { modulus }[\mathrm{GPa}]\end{array}$ & $\begin{array}{c}\text { Hardness } \\
{[\mathrm{GPa}]}\end{array}$ & $\begin{array}{c}\text { Elastic modulus } \\
{[\mathrm{GPa}]}\end{array}$ & $\begin{array}{c}\text { Tensile strength } \\
{[\mathrm{MPa}]}\end{array}$ & $\begin{array}{c}\text { Shear strength } \\
{[\mathrm{MPa}]}\end{array}$ & $\begin{array}{c}\text { Compression } \\
\text { modulus }[\mathrm{GPa}]\end{array}$ & $K_{I C}\left[\mathrm{MPa}(\mathrm{m})^{1 / 2}\right]$ \\
\hline E1 & $4.02 \pm 0.03$ & $0.265 \pm 0.003$ & $3.08 \pm 0.08$ & $73.7 \pm 0.6$ & $54.0 \pm 1.0$ & $3.08 \pm 0.05$ & $2.18 \pm 0.13$ \\
E2 & $4.05 \pm 0.06$ & $0.279 \pm 0.005$ & $3.19 \pm 0.15$ & $72.7 \pm 0.4$ & $53.3 \pm 0.9$ & $3.42 \pm 0.05$ & $1.81 \pm 0.13$ \\
\hline
\end{tabular}

each case). An Instron 8801 universal testing machine was used with a $10 \mathrm{kN}$ load cell and speed test of $10 \mathrm{~mm} / \mathrm{min}$.

\subsection{Epoxy/GF/CNTs Composite Characterization. The IFSS} was determined based on the push-out test, using a Hysitron TI 950 Triboindenter system, equipped with a $5 \mu \mathrm{m}$ diameter diamond flat punch. The fiber was loaded at a displacement rate of $50 \mathrm{~nm} / \mathrm{s}$. Both the testing procedure and sample preparation were performed according to [23], by preparing a thin-sheet of a composite and pushing individual fibers until fiber sliding occurs. The IFSS was computed from the maximum load, by as the maximum shear stress at the fibermatrix interface. Two samples per material were performed and at least 20 fibers were pushed per sample.

To study the intraply fracture behavior, the three-point bending test was performed according to the ASTM D5045 standard (10 tests per material). The testing samples geometry was as follows: $4.3 \mathrm{~mm}$ thickness, $3 \mathrm{~mm}$ width, and $22 \mathrm{~mm}$ support span. The notch length was 0.5 times the thickness, machined with a $150 \mu \mathrm{m}$ diameter diamond wire. A Kammrath \& Weiss stage micromachine was used with a $1000 \mathrm{~N}$ load cell and a speed test of $100 \mu \mathrm{m} / \mathrm{min}$. Some tests were performed on a scanning electron microscope (Zeiss EVO MA-15) to examine the damage mechanism before failure.

The short beam test was used to compute the interlaminar shear strength (ILSS) according to the ASTM D2344 standard (10 tests per material). The geometry of the testing samples was as follows: $4.3 \mathrm{~mm}$ thickness, $4.9 \mathrm{~mm}$ width, and $22 \mathrm{~mm}$ support span. The tests were performed in a Kammrath \& Weiss stage micromachine with a $1000 \mathrm{~N}$ load cell and a speed test of $15 \mu \mathrm{m} / \mathrm{s}$.

To study the macroscopic behavior, an out-of-plane compression test was performed according to ASTM D695 (10 tests per material). According authors [24, 25], the sample shape has no influence on result for unidirectional laminates, for this reason a cubic shape is preferred, since their manufacture is simple in comparison with cylindrical shapes. This research is a comparative study; therefore cubic specimens $10 \mathrm{~mm}$ side were used. The tests were performed in a universal testing machine (Instron 8801) with a $100 \mathrm{kN}$ load cell. The test speed was $1.2 \mathrm{~mm} / \mathrm{min}$, the compression plates were lubricated, and a $2 \mathrm{~mm}$ strain gauge was used for the strain measurement.

\section{Results and Discussion}

3.1. Epoxy/CNTs. The mechanical properties obtained for the different concentrations of CNTs into epoxy matrix are summarized in Table 2 . The reduced moduli, obtained by nanoindentation and the results of the tensile and shear tests, show no significant changes (less than $3 \%$ of variation) with CNT incorporation. Despite the fact that several articles [6-11, 26] indicated an enhancement of the mechanical properties of polymeric resins by the incorporation of CNTs, it should be noted that the epoxy resin used in this work has a high stiffness compared to other related research studies. This is in agreement with previous studies by $\mathrm{Ci}$ and Bai [6] who concluded that the resin stiffness decreases the potential positive effect of CNTs. In particular, it can extrapolate from their research that the effect of CNTs on the mechanical behavior of epoxy resins was negligible for resins with elastic moduli over $2.45 \mathrm{GPa}$.

On the contrary, incorporation of CNTs results in an average increase of $6 \%$ in hardness, compared to the neat epoxy resin, this result is consistent with Tehrani et al. [27] where comparable materials were studied. Based on the hardness-compression strength factor established by Rodríguez et al. [28], the results indicate an increase in the compression strength of the nanocomposite. Moreover, the compression modulus also shows an increase of $11 \%$, with the incorporation of CNTs (Table 2). The rise on the compression strength and modulus of an epoxy resin due to the CNTs was also evidenced by Ma et al. [29] and Naik et al. [30].

A clear reduction in the KIC with the incorporation of CNTs was obtained, contrary to other studies $[9,11,26]$. An analysis of the fracture surfaces, as summarized in Figure 1, indicates a smooth fracture surface for the neat resin (a) and a rougher surface of the CNT reinforced resins, as shown in (b). Gojny et al. [8], Ayatollahi et al. [11] and Srivastava and Singh [31] observed similar increases in the roughness of the fracture surfaces with CNT incorporation, which was attributed to the blocking effect of CNTs to crack expansion and changes in the crack propagation direction [32], resulting in a fracture mechanism similar to the one exhibited in ductile failure. According to $[8,33]$, nonfunctionalized CNTs produce a weak interfacial adhesion between the CNTs, then can act as defects, and therefore degrade the property; nevertheless according to [34] these defects can be beneficial to produce ductility. When the crack tip grows, the CNTs debonded from the epoxy produce a local stresses increment at the crack tip [35]. Next, the debonded CNTs act as voids in the epoxy that enables the polymer to deform plastically. Therefore, the decrease of KIC suggests that the nonfunctionalized CNTs act as stress concentrators in the crosslinked polymer network.

3.2. Epoxy/GF/CNTs. The IFSS was measured by a pushout test and the results over a large number of tests show a consistent increase in the average IFSS of $22 \%$ with the incorporation of CNTs (see Table 3). As observed in [23] (the research that precedes this one that focuses the determination of the IFSS by push-in and push-out test on nanoreinforced composites), the increase in the IFSS and the changes in the 
TABle 3: Properties of the epoxy/GF/CNTs composites.

\begin{tabular}{lcccc}
\hline Material & IFSS $[\mathrm{MPa}]$ & $G_{I}\left[\mathrm{KJ} / \mathrm{m}^{2}\right]$ & Compression modulus [GPa] & Compression strength [MPa] \\
\hline EG1 & $58.37 \pm 6.64$ & $1.83 \pm 0.29$ & $8.71 \pm 0.15$ & $203.54 \pm 15.16$ \\
EG2 & $72.04 \pm 4.34$ & $1.83 \pm 0.10$ & $9.27 \pm 0.14$ & $215.23 \pm 20.22$ \\
\hline
\end{tabular}

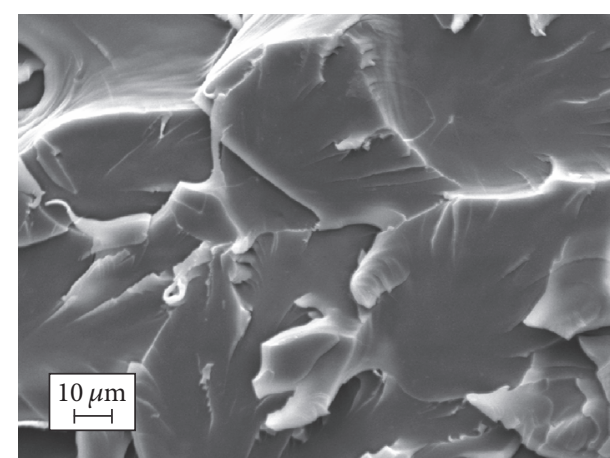

(a)

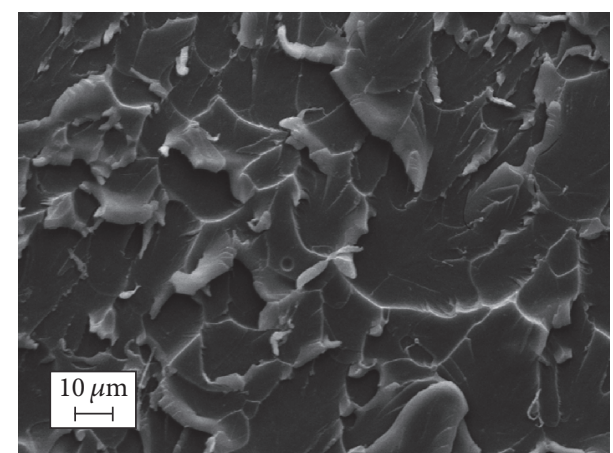

(b)

FIGURE 1: Fracture surface of the neat epoxy resin in (a) E1 and the CNT reinforced epoxy resins in (b) E2.

interface failure mode undoubtedly indicate that the CNTs act as anchoring points delaying the fiber-resin interface failure.

To get a better understanding of the crack propagation mechanisms, intraply fracture tests were also carried out in situ inside a scanning electron microscope. Figure 2 illustrates an example for a composite, with a series of snapshots showing the evolution of damage at different stages of the load-displacement curve. The first damage event occurs with the nucleation of a microcrack that grows between the tows at the root of the notch as early as point 2 in the loaddisplacement curve. Further loading results in the formation of crack branches in adjacent tows, with the number of crack branches increasing while the composite is elastically loaded from 3 to 5 , while the resin pockets between tows remain undamaged. Finally, at the maximum load (5), a continuous microcrack develops through linking of several crack branches at the fiber tows by failure of the resin pockets. This crack branching mechanism is responsible for the high energy absorption of the fracture process, supporting the high values of fracture energy obtained in the composite materials.

A classical mechanical analysis for fracture calculates the total fracture energy $G_{I T}$ according to the following:

$$
G_{I T}=\frac{A_{T}}{W * l_{C}}
$$

where $A_{T}, W$, and $l_{C}$ are the area under the load-displacement curve and the width and crack length, respectively. Table 3 summarizes the results, indicating that the total fracture energy was not affected by the introduction of CNTs (see Table 3). Now, Figure 5 shows selected normalized loaddisplacement curves corresponding to fracture test for FRC and nFRC. Normalization was performed according to the maximum load achieved for each material. Differences are found between the curves in the crack propagation path.

In view of these results, considering the shape of the loaddisplacement curves (Figure 3), it is proposed to separate the total fracture energy $G_{I T}$ as the sum of damage initiation energy $G_{D}$ and a propagation energy $G_{P}$; we have

$$
G_{I T}=G_{D}+G_{P}=\frac{A_{D}+A_{P}}{W * l_{C}},
$$

where $A_{D}$ and $A_{P}$ are the area under the elastic loading curve and the area under the curve after the maximum load is achieved, as defined in Figure 4. The results obtained using (2) are plotted in Figure 5 and suggest a decrease in the damage initiation energy and an increase in the propagation energy with addition of CNTs. The differences observed are in good agreement with the modification of $K_{I C}$ (matrix) and the increase of IFSS observed with CNT incorporation at the micromechanical level. That asseveration also is supported by the appearance of particular features on the fracture surfaces as shown in Figure 6, where the addition of CNTs in the composite changes the failure mode from brittle (Figure 6(a)) to more ductile (Figure 6(b)), with the torn resin between fibers showing evidence of plastic deformation [23].

In summary, on the one hand, the addition of CNTs contributes to an increase of the IFSS of the glass fibers and a more ductile interface failure contributing to higher propagation energy. On the other hand, the CNTs contribute to a decrease in $K_{I C}$ of the resin due to the weak bonding of the nonfunctionalized CNTs to the epoxy resin. As a result, the total fracture energy is weakly affected by the CNT content despite the noticeable differences in the fracture modes.

Similarly, Figure 7 shows the ILSS obtained as a function of CNT content, by means of the short beam test. In this case, the addition of CNTs produce a negative effect with a reduction of $7 \%$ in the ILSS for the $0.5 \mathrm{wt}$. $\%$ CNT composite. 


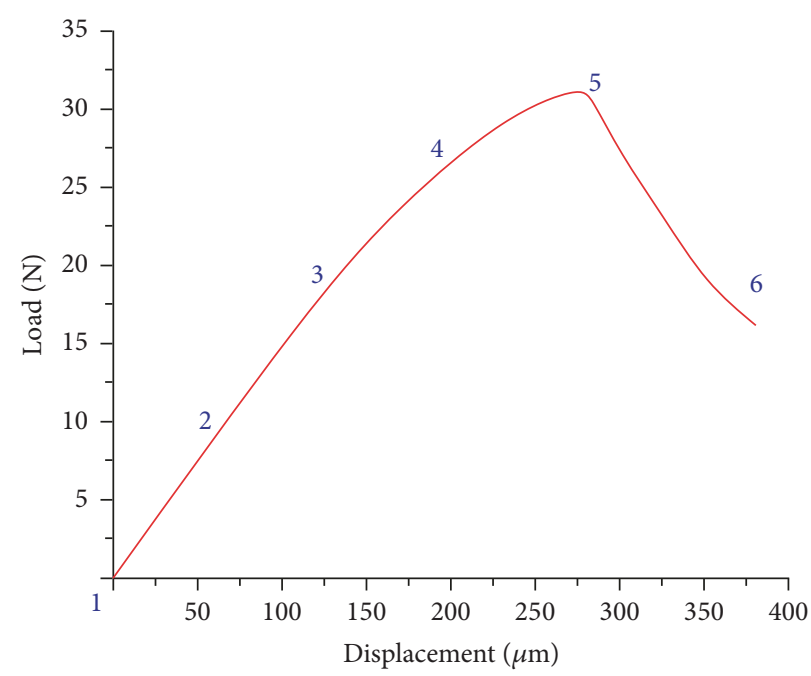

(a)

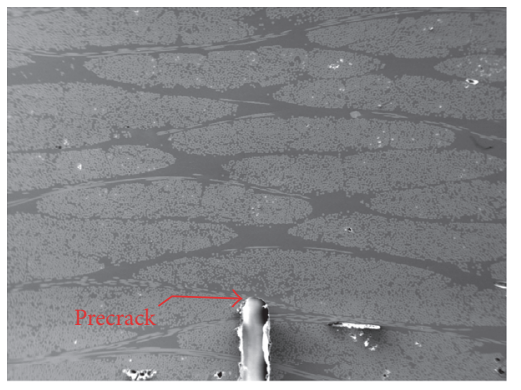

(1)

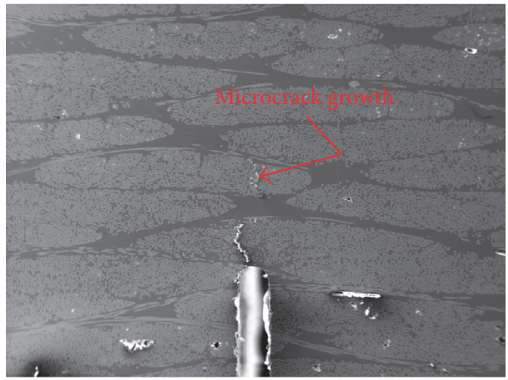

(3)

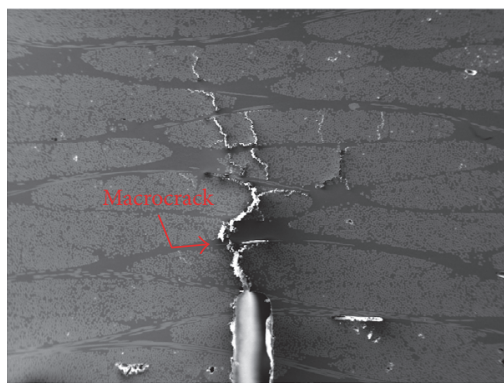

(5)

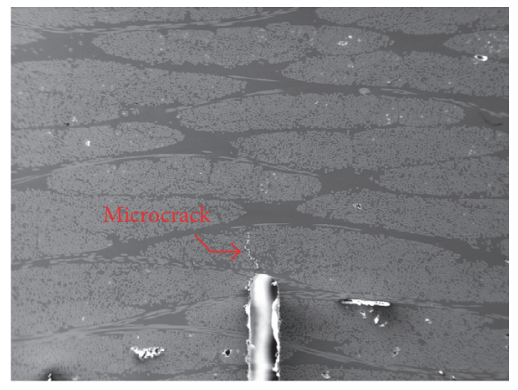

(2)

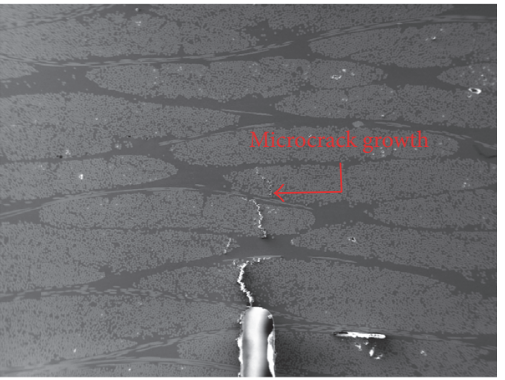

(4)

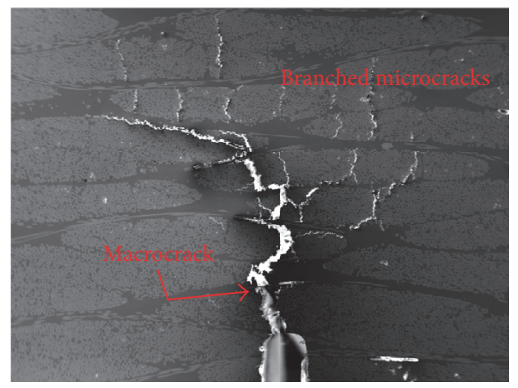

(6)

(b)

FIGURE 2: In situ mode I interlaminar fracture test. (a) Schematic load-displacement of the intraply fracture test and (b) intraply microcrack evolution for composite. 


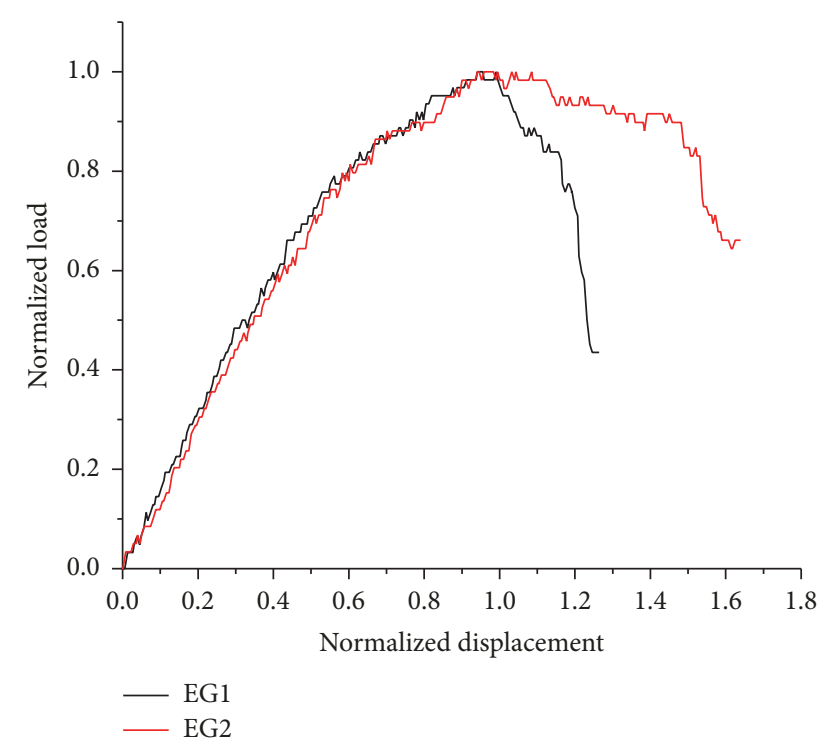

FIGURE 3: Selected experimental curves of the mode I intralaminar fracture test of the FRC (EG1) and the nFRC (EG2).

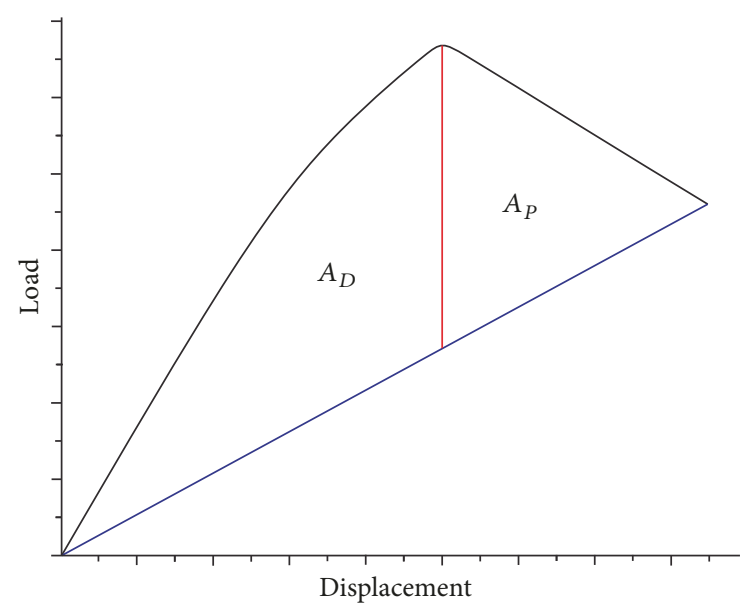

Figure 4: Schematic definition of $A_{D}$ and $A_{P}$.

The CNTs content is similar to that documented in [34, 36]. Generally, interlaminar shear failure involves several fracture mechanisms that occur during delamination, being the most important the matrix deformation and fracture and fiber/matrix interface debonding [37]. Thus in the case of the short beam test, failure can occur either within or between the plies.

Considering that the zone between the plies is resin rich zones and the fact that the CNTs have a negative effect on the fracture toughness of the resin (with a reduction of 17\%), it is safe to assume that, despite the IFSS property that shows an important contribution from fiber debonding, the ILSS is mostly dominated by the resin properties. These findings differ from the results obtained in Chandrasekaran et al. in [7].

Finally, the compression tests indicate an increase of $6 \%$ due to the addition of CNTs for both the maximum

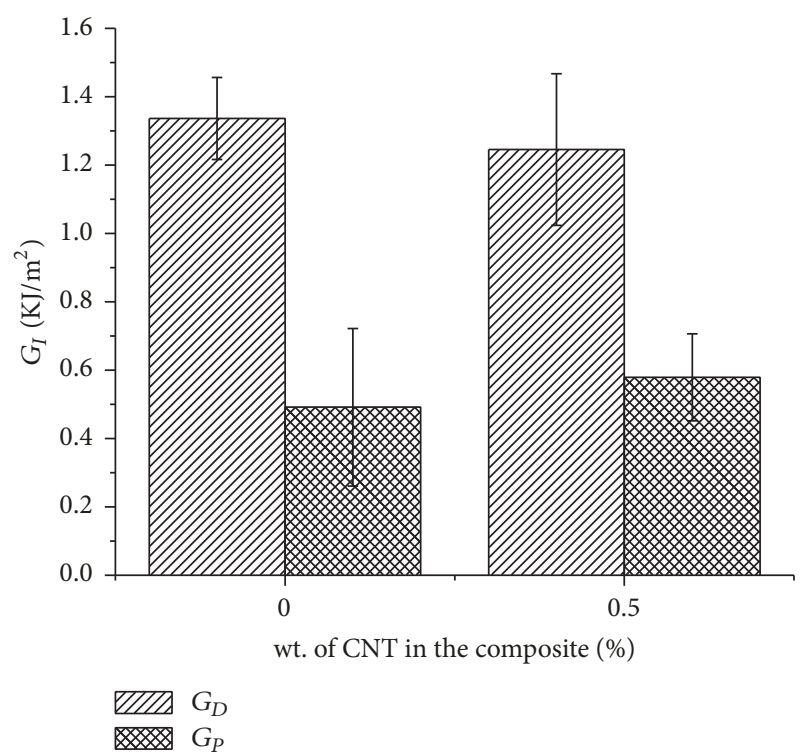

FIgURE 5: Energy computed as a function of the CNT content.

strength and the compression modulus (see Table 3), behavior that was also observed by Sharma and Lakkad [38]. According to González and LLorca [1], failure under outof-plane compression occurs either by shear of the matrix or debonding at the fiber-matrix interface. This work shows that the shear strength of the resin is insensitive to the CNT content, but the hardness and compressive strength were increased. Considering that the IFSS was also increased, it is not surprising that the out-of-plane compressive strength of the nFRC shows a clear improvement.

Figure 8 shows two common failure patterns on the outof-plane compression fractured surface. Figure 8(a), which corresponds to an epoxy/GF specimen, shows signs of fibermatrix interface brittle failure. Figure 8(b), corresponding to a specimen of epoxy/GF/CNTs at a $0.5 \mathrm{wt}$.\% concentration, shows a greater adhesion of resin in the fibers than for the epoxy/GF specimen, which is associated with an increased interface strength and is consistent with the push-out test results.

\section{Conclusions}

The effect of adding CNTs on the mechanical properties of a glass fiber-reinforced epoxy matrix composite was investigated under different loading modes. Moreover, the contribution of CNTs to the overall behavior was elucidated based on the contribution of the CNTs to the properties of the resin and the resin-fiber interface.

Results show that the addition of CNTs to the epoxy resin contribute to either a slight increase or no effect in the elastic modulus, tensile, and shear strength, which was associated with the intrinsic high stiffness and fracture toughness of the epoxy resin used in this study. The main beneficial effect of the CNTs on the resin properties was observed in the hardness, with an increase of $6 \%$, which indicates that in compression the CNTs contribute to the load 


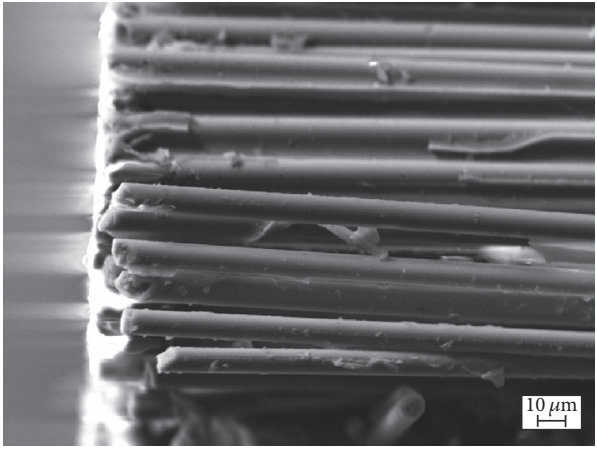

(a)

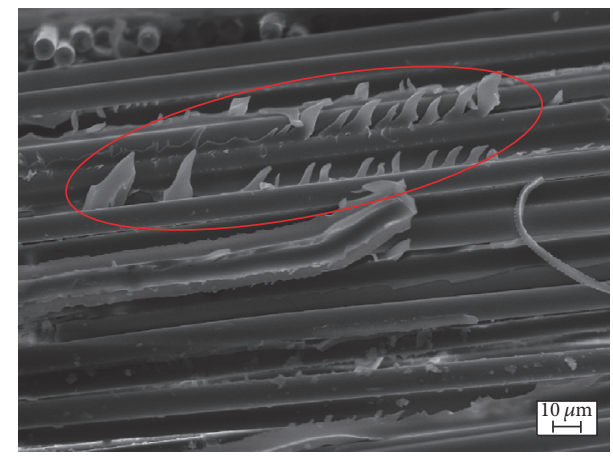

(b)

FIGURE 6: Scanning electron micrographs of intralaminar fracture surface: (a) EG1 and (b) EG2.

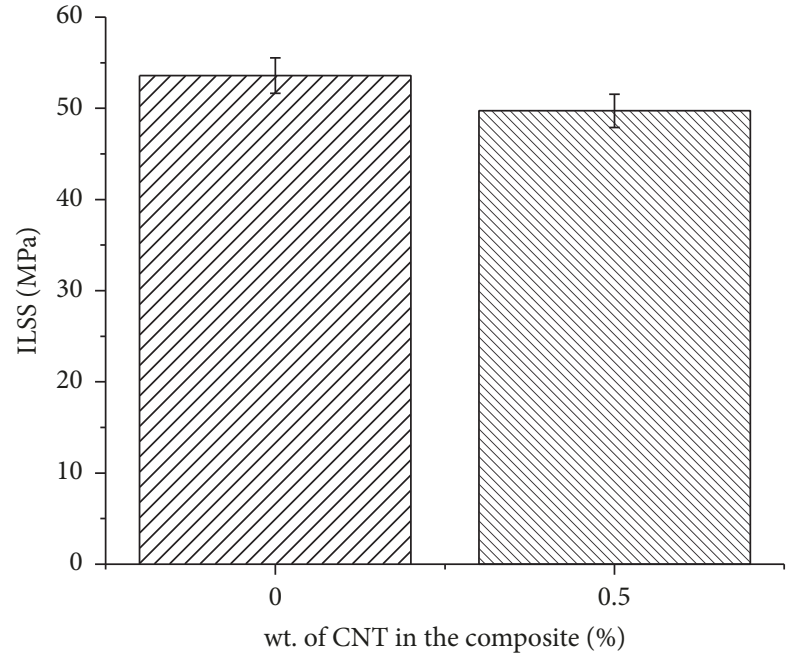

FIGURE 7: ILSS obtained by the short beam test as function of the CNT content.

bearing capability of the polymer network, hence increasing its compressive strength. However, the fracture toughness of the resin was negatively affected, with a decrease of $17 \%$, possibly indicating that the nonfunctionalized CNTs produce stress concentration which decrease the strength of the polymer network. This phenomenon was evidenced by SEM inspection of the fractured surfaces. In the case of the epoxy/GF/CNTs composite, a clear increase of the fiber/matrix interfacial bonding was observed with CNT addition, with an increment of $22 \%$ in the average IFSS.

As a result of the opposite effects that the CNT additions display on the resin and the resin-fiber interface, the intraply fracture energy of the composite was not affected by CNT content, because the beneficial addition on the IFSS was counteracted by the decrease in the fracture toughness of the resin. Independently of CNT contents, all composites showed a microcrack branching crack propagation mechanism, with the CNT content contributing to a more ductile behavior as a result of the higher IFSS, but with little effect on the total fracture energy.

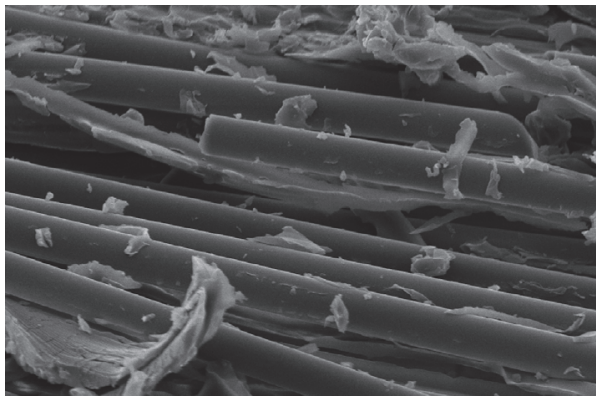

(a)

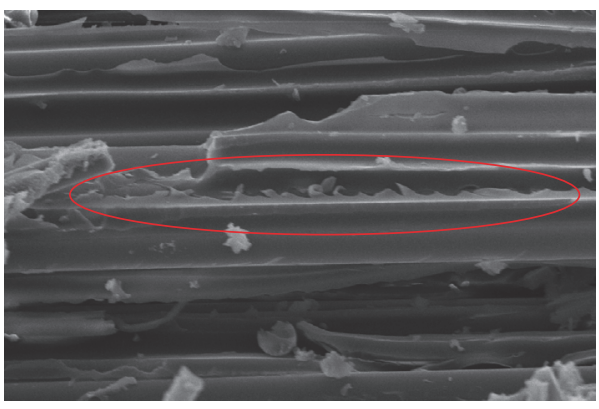

(b)

FIGURE 8: Scanning electron micrographs of interfacial failure for the compression specimen: (a) EG1 and (b) EG2.

On the contrary, the CNT content contributed to a decrease in the interlaminar shear strength, as this mode of failure was dominated by the strength of the resin rich zones separating the fiber tows.

Finally, the out-of-plane compression properties increased by $6 \%$ with CNT content as this mode of deformation was mainly controlled by the compressive strength of the resin and the IFSS that are both positively affected by the incorporation of CNTs.

\section{Conflicts of Interest}

The authors declare that there are no conflicts of interest regarding the publication of this paper. 


\section{Acknowledgments}

The financial support by Conicyt through the project Fondecyt de Iniciacion 11160285 led by Carlos Medina is gratefully acknowledged.

\section{References}

[1] C. González and J. LLorca, "Mechanical behavior of unidirectional fiber-reinforced polymers under transverse compression: microscopic mechanisms and modeling," Composites Science and Technology, vol. 67, no. 13, pp. 2795-2806, 2007.

[2] E. Totry, C. González, and J. LLorca, "Failure locus of fiberreinforced composites under transverse compression and outof-plane shear," Composites Science and Technology, vol. 68, no. 3-4, pp. 829-839, 2008.

[3] T. J. Vaughan and C. T. McCarthy, "A micromechanical study on the effect of intra-ply properties on transverse shear fracture in fibre reinforced composites," Composites Part A: Applied Science and Manufacturing, vol. 42, no. 9, pp. 1217-1228, 2011.

[4] T. J. Vaughan and C. T. McCarthy, "Micromechanical modelling of the transverse damage behaviour in fibre reinforced composites," Composites Science and Technology, vol. 71, no. 3, pp. 388396, 2011.

[5] R. Lane, S. Hayes, and F. Jones, "Fibre/matrix stress transfer through a discrete interphase: 2 . High volume fraction systems," Composites Science and Technology, vol. 61, no. 4, pp. 565-578, 2001.

[6] L. Ci and J. Bai, "The reinforcement role of carbon nanotubes in epoxy composites with different matrix stiffness," Composites Science and Technology, vol. 66, no. 3-4, pp. 599-603, 2006.

[7] V. C. S. Chandrasekaran, S. G. Advani, and M. H. Santare, "Influence of resin properties on interlaminar shear strength of glass/epoxy/MWNT hybrid composites," Composites Part A: Applied Science and Manufacturing, vol. 42, no. 8, pp. 1007-1016, 2011.

[8] F. H. Gojny, M. H. G. Wichmann, B. Fiedler, and K. Schulte, "Influence of different carbon nanotubes on the mechanical properties of epoxy matrix composites - a comparative study," Composites Science and Technology, vol. 65, no. 15-16, pp. 23002313, 2005.

[9] C. Ma, H.-Y. Liu, X. Du, L. Mach, F. Xu, and Y.-W. Mai, "Fracture resistance, thermal and electrical properties of epoxy composites containing aligned carbon nanotubes by low magnetic field," Composites Science and Technology, vol. 114, pp. 126-135, 2015.

[10] A. H. Korayem, M. R. Barati, G. P. Simon, X. L. Zhao, and W. H. Duan, "Reinforcing brittle and ductile epoxy matrices using carbon nanotubes masterbatch," Composites Part A: Applied Science and Manufacturing, vol. 61, pp. 126-133, 2014.

[11] M. R. Ayatollahi, S. Shadlou, and M. M. Shokrieh, "Fracture toughness of epoxy/multi-walled carbon nanotube nanocomposites under bending and shear loading conditions," Materials and Design, vol. 32, no. 4, pp. 2115-2124, 2011.

[12] A. Godara, L. Gorbatikh, G. Kalinka et al., "Interfacial shear strength of a glass fiber/epoxy bonding in composites modified with carbon nanotubes," Composites Science and Technology, vol. 70, no. 9, pp. 1346-1352, 2010.

[13] R. J. Sager, P. J. Klein, D. C. Lagoudas et al., "Effect of carbon nanotubes on the interfacial shear strength of T650 carbon fiber in an epoxy matrix," Composites Science and Technology, vol. 69, no. 7-8, pp. 898-904, 2009.
[14] P. Lv, Y.-Y. Feng, P. Zhang, H.-M. Chen, N. Zhao, and W. Feng, "Increasing the interfacial strength in carbon fiber/epoxy composites by controlling the orientation and length of carbon nanotubes grown on the fibers," Carbon, vol. 49, no. 14, pp. 4665-4673, 2011.

[15] L. Yang, X. He, L. Mei, L. Tong, R. Wang, and Y. Li, "Interfacial shear behavior of 3D composites reinforced with CNT-grafted carbon fibers," Composites Part A: Applied Science and Manufacturing, vol. 43, no. 8, pp. 1410-1418, 2012.

[16] M. Li, Y. Gu, Y. Liu, Y. Li, and Z. Zhang, "Interfacial improvement of carbon fiber/epoxy composites using a simple process for depositing commercially functionalized carbon nanotubes on the fibers," Carbon, vol. 52, pp. 109-121, 2013.

[17] Z.-J. Wang, D.-J. Kwon, G.-Y. Gu et al., "Mechanical and interfacial evaluation of $\mathrm{CNT} /$ polypropylene composites and monitoring of damage using electrical resistance measurements," Composites Science and Technology, vol. 81, pp. 69-75, 2013.

[18] V. Romanov, S. V. Lomov, I. Verpoest, and L. Gorbatikh, "Interfiber stresses in composites with carbon nanotube grafted and coated fibers," Composites Science and Technology, vol. 114, pp. 79-86, 2015.

[19] V. S. Romanov, S. V. Lomov, I. Verpoest, and L. Gorbatikh, "Modelling evidence of stress concentration mitigation at the micro-scale in polymer composites by the addition of carbon nanotubes," Carbon, vol. 82, no. C, pp. 184-194, 2015.

[20] V. S. Romanov, S. V. Lomov, I. Verpoest, and L. Gorbatikh, "Stress magnification due to carbon nanotube agglomeration in composites," Composite Structures, vol. 133, pp. 246-256, 2015.

[21] A. Jiménez-Suárez, M. Campo, M. Sánchez, C. Romón, and A. Ureña, "Influence of the functionalization of carbon nanotubes on calendering dispersion effectiveness in a low viscosity resin for VARIM processes," Composites Part B: Engineering, vol. 43, no. 8, pp. 3482-3490, 2012.

[22] W. C. Oliver and G. M. Pharr, "Improved technique for determining hardness and elastic modulus using load and displacement sensing indentation experiments," Journal of Materials Research, vol. 7, no. 6, pp. 1564-1580, 1992.

[23] C. Medinam, J. M. Molina-Aldareguía, C. González, M. F. Melendrez, P. Flores, and J. Llorca, "Comparison of push-in and push-out tests for measuring interfacial shear strength in nanoreinforced composite materials," Journal of Composite Materials, vol. 50, no. 12, pp. 1651-1659, 2015.

[24] B. C. Kim, D. C. Park, B. J. Kim, and D. G. Lee, “Throughthickness compressive strength of a carbon/epoxy composite laminate," Composite Structures, vol. 92, no. 2, pp. 480-487, 2010.

[25] V. L. Tagarielli, G. Minisgallo, A. J. McMillan, and N. Petrinic, "The response of a multi-directional composite laminate to through-thickness loading," Composites Science and Technology, vol. 70, no. 13, pp. 1950-1957, 2010.

[26] T. H. Hsieh, A. J. Kinloch, A. C. Taylor, and I. A. Kinloch, "The effect of carbon nanotubes on the fracture toughness and fatigue performance of a thermosetting epoxy polym," Journal of Materials Science, vol. 46, no. 23, pp. 7525-7535, 2011.

[27] M. Tehrani, M. Safdari, and M. S. Al-Haik, "Nanocharacterization of creep behavior of multiwall carbon nanotubes/epoxy nanocomposite," International Journal of Plasticity, vol. 27, no. 6, pp. 887-901, 2011.

[28] M. Rodríguez, J. M. Molina-Aldareguía, C. González, and J. Llorca, "Determination of the mechanical properties of amorphous materials through instrumented nanoindentation," Acta Materialia, vol. 60, no. 9, pp. 3953-3964, 2012. 
[29] P. Ma, G. Jiang, Q. Chen, H. Cong, and X. Nie, "Experimental investigation on the compression behaviors of epoxy with carbon nanotube under high strain rates," Composites Part B: Engineering, vol. 69, pp. 526-533, 2015.

[30] N. K. Naik, K. S. Pandya, V. R. Kavala, W. Zhang, and N. A. Koratkar, "High-strain rate compressive behavior of multiwalled carbon nanotube dispersed thermoset epoxy resin," Journal of Composite Materials, vol. 49, no. 8, pp. 903-910, 2016.

[31] V. K. Srivastava and S. Singh, "A micro-mechanical model for elastic modulus of multi-walled carbon nanotube/epoxy resin composite," International Journal of Composite Materials, vol. 2, no. 2, pp. 1-6, 2012.

[32] K. Yang, M. Gu, Y. Guo, X. Pan, and G. Mu, "Effects of carbon nanotube functionalization on the mechanical and thermal properties of epoxy composites," Carbon, vol. 47, no. 7, pp. 17231737, 2009.

[33] K. Guru, S. B. Mishra, and K. K. Shukla, "Effect of temperature and functionalization on the interfacial properties of CNT reinforced nanocomposites," Applied Surface Science, vol. 349, pp. 59-65, 2015.

[34] A. Godara, L. Mezzo, F. Luizi et al., "Influence of carbon nanotube reinforcement on the processing and the mechanical behaviour of carbon fiber/epoxy composites," Carbon, vol. 47, no. 12, pp. 2914-2923, 2009.

[35] R. B. Ladani, S. Wu, A. J. Kinloch et al., "Improving the toughness and electrical conductivity of epoxy nanocomposites by using aligned carbon nanofibres," Composites Science and Technology, vol. 117, pp. 146-158, 2015.

[36] M. Siegfried, C. Tola, M. Claes, S. V. Lomov, I. Verpoest, and L. Gorbatikh, "Impact and residual after impact properties of carbon fiber/epoxy composites modified with carbon nanotubes," Composite Structures, vol. 111, no. 1, pp. 488-496, 2014.

[37] J. Zhang, S. Ju, D. Jiang, and H.-X. Peng, "Reducing dispersity of mechanical properties of carbon fiber/epoxy composites by introducing multi-walled carbon nanotubes," Composites Part B: Engineering, vol. 54, no. 1, pp. 371-376, 2013.

[38] S. P. Sharma and S. C. Lakkad, "Compressive strength of carbon nanotubes grown on carbon fiber reinforced epoxy matrix multi-scale hybrid composites," Surface and Coatings Technology, vol. 205, no. 2, pp. 350-355, 2010. 

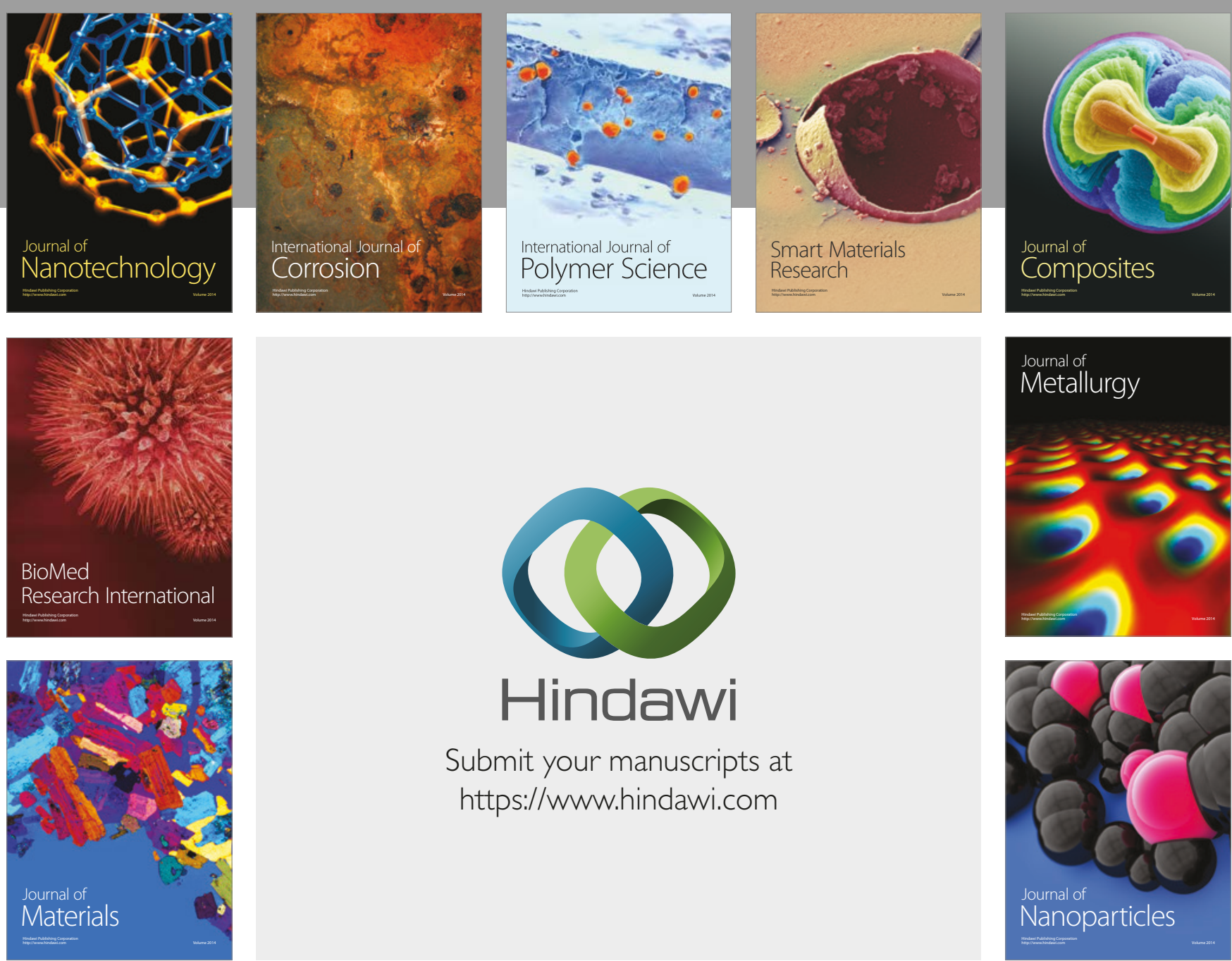

\section{Hindawi}

Submit your manuscripts at

https://www.hindawi.com
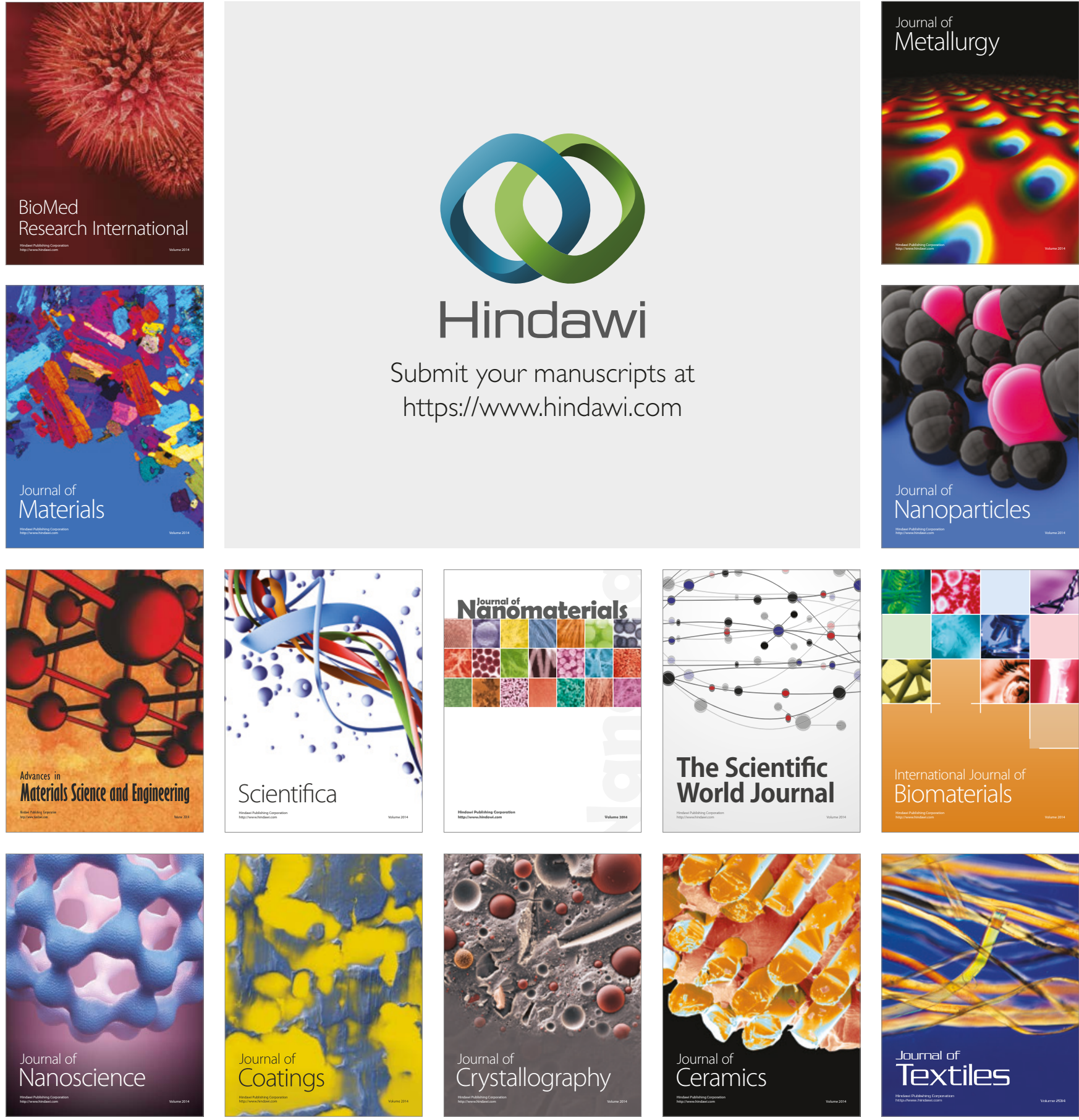

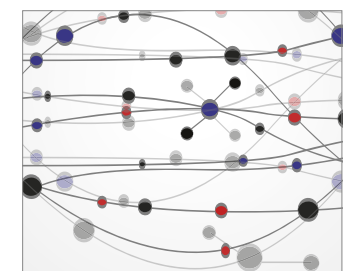

The Scientific World Journal
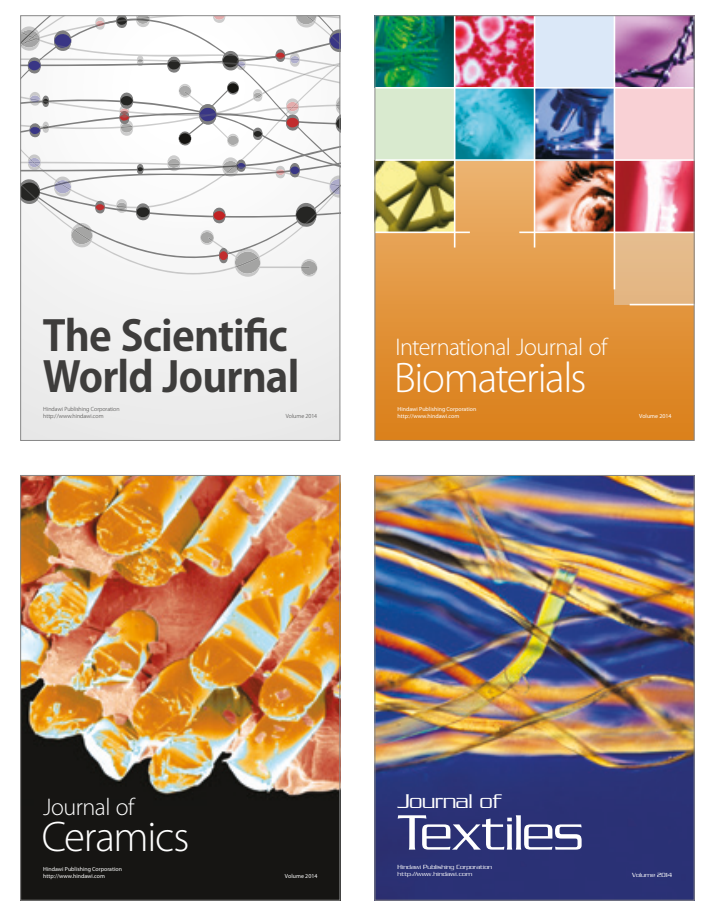